\title{
2Book Reviems.
}

Mind and Its Disordcrs. A Text-Book for Students and Practitioners of Medicine. By W. H. B. StodDaRD, M. D., F.R. C. P., Lecturer on Mental Diseases, St. Thomas's Hospital Medical School, State Resident Physician and Medical Superintendent Bethlem Royal Hospital, etc. Third Edition with Illustrations. (Philadelphia: P. Blakiston's Son Co., rgrg.)

The most striking feature in the third edition of "Mind and Its Disorders" is the change in the attitude of the author toward Freudian psychology. The following quotations tell their own story. In the preface to the first edition he says: "The book is divided into three sections. In the first which deals with modern psychology, an attempt is made to correlate mental processes with their physical substrata in the nervous system, the transcendental psychology of modern schoolmen being ignored as useless to the practical physician of to-day." A direct reversal of this view appears in the third edition preface as follows: "Since the last edition I have fundamentally changed my attitude toward mental disease, having personally investigated very many patients by the psychoanalytical method and thus been convinced of the truth of Freud's doctrines. Mental disease can only be understood by studying the psychology of the unconscious mind of patients, and the physical manifestations of a functional nervous disorder must be regarded as secondary, not primary, as I taught in the first edition."

Stoddard's surrender to Freudianism is not a grudging or half-hearted one. Horse, foot and dragoons he has gone over to the enemy. The most literal interpretation of psychoanalysis in theory and practice is accepted without reservation. The mental elasticity and freedom from prejudice which such a transformation denotes compells admiration. At the same time those friendly to Freudianism and sympathetic with the psychogenic approach to mental disorders, may feel that their case would have been strengthened in greater degree if the conversion of a former opponent had been less overwhelming. The impression is also received that assimilation of the new doctrine is not wholly complete. Throughout the discussion run separate currents; the old descriptive psychiatry alternating with the analytical viewpoint, often to the detriment of unity and clearness. To borrow chemical terms, there is much to be found that is mixture rather than compound.

The third edition follows the others in general arrangement. The first section deals with normal psychology; the second with the psychology of 
the insane; and the third gives a comprehensive survey of mental diseases. There are, in addition, chapters devoted to general treatment and to legal phases of insanity, and appendices describing laboratory technique. The whole text is amply illustrated. To include all this in one modest sized book is indeed an ambitious achievement. The faults which might be predicted from trying to condense a psychiatric library into one volume are not lacking. There is much that is dogmatic, style and construction are sacrificed for brevity, and many important subjects are treated with encyclopedic terseness.

Startling and original doctrine is plentiful. Some examples are as follows. In the chapter on exopthalmic goitre, the plea is made that this disease be classed with the anxiety neuroses instead of being considered a disturbance of the thyroid gland. The flat statement is made, (p. 223) "as a further argument I may anticipate by stating that the disease is curable by psychoanalysis." He further says, (p. 228) "psychoanalysis reduces the pulse rate practically to normal in a month or six weeks, and the other symptoms are gradually ameliorated in a few months." The term neurasthenia is defined as a state of easy fatigability due to partially or completely repressed autoeroticism. In regard to treatment he says, (p. 217) "There is only one certain cure for neurasthenia, viz. psychoanalysis but inasmuch as most neurasthenics cannot afford this mode of treatment can anything else be done to ameliorate their condition?" Fortunately for the afflicted the answer is yes, they can be treated as cases of chronic nervous exhaustion, which condition closely resembles neurasthenia, with fair prospect of success.

In spite of his psycho-analytical conversion, the author favors toxic processes as the cause of manic depressive insanity. He constructs an interesting hypothesis of consummate simplicity based on the contrasting motor manifestations in mania and depression. To the reviewer the evidence for his conclusions seems most flimsy. The theory is summarized as follows; (p. 295) " $I$. That in mania an irritating product is formed within the cortical neurons....2. That in melancholia, a paralyzing product is formed within the cortical neurons.....3. That in agitated melancholia there is a combination of deleterious influences, viz. a paralyzing product within the cortical neurons and also an iritating body in the plasma bathing the nerve cell. ...4. And that in a few cases of mania, there is, in addition to the irritating body within the nerve cell, an irritating body in the plasma bathing the nerve cell." This conception of cause does not prevent him from waxing enthusiastic over interval treatment with psychoanolysis to ward off further attacks.

In marked contrast to these conceptions of pathology and treatment is a statement concerning paranoia (p. 309), "Although psychoanalysis has succeeded in elucidating the cause of the disease it fails as a method of treatment." In outlining the therapy of acute depressions advantage is taken of the fact that they are sometimes benefited by intercurrent infections and it is advised (p. 275) that a state of artificial hyperthyroidism 
be produced and excellent results are claimed for the procedure. In the consideration of dementia precox scant attention is paid to the psychological mechanisms which may be concerned. A short non-committal paragraph summarizes Jung's theory, while evidence for the presence of auto-intoxication is detailed with favorable consideration. Analytical possibilities are dismissed with a sentence (p. 316), "Apart from the difficulty of psycho-analysis in dementia pracox, this process is of little or no therapeutic value for this disease."

A novel treatment for paresis is suggested which has the virtue at least of offering consolation to those of the bibulous suffering from this disease. A plentiful supply of alcohol, preferably brandy and soda, is given to paretics on the theory that it finds its way past the barrier of the choroid plexus and exerts some therapeutic action on the cerebro-spinal fluid. Hexamine is also recommended. "The least that can be said for such treatment," says Dr. Stoddart (p. 440), "is that no general paralytic patient of mine ever has convulsions."

The reviewer in emphasizing what seem to be weak points in this book does not wish to overlook valuable features which are present. The author appears at his best as an accurate observer in the clinical field, particularly in regard to the physical manifestations in various mental disorders. Note should also be made of his discussion of treatment. The detailed common sense directions for routine management of mental cases will be welcomed by the student who is so often baftled by the generalities with which he must be satisfied in many works on psychiatry.

M. W. Peck.

Bulletin of Iowa Instibutions (Under the Board of Control). Published Quarterly. Volume XXI. 1919.

This bulletin is the record of the quarterly conferences which are held by the Iowa Board of Control and the officers of the institutions under its charge. It is very obvious that such conferences are helpful and the record of them is certainly of value to those participating. It is also helpful to those who cannot attend. The subjects discussed vary from administrative to scientific and hence appeal to all. Best of all perhaps is the evidence that the Iowa Board of Control is making a sincere and honest effort to give the best care possible to its charges.

W. R. D.

Sex Attraction. A Lecture given at the Michigan State Normal School. By Victor C. Vaughan, Sc. D., M. D., LL. D. Price 50 cents. (St. Louis: C. V. Mosby Company, 1920.)

This is "an attempt to state in a broad way the physiologic relation between the sexes." The chief criticism which can be made is that the subject is disposed of in too brief and casual a way, and hence lacks the force which 